\title{
Author Correction: Inhibitory mechanism of reveromycin $A$ at the tRNA binding site of a class I synthetase
}

Bingyi Chen, Siting Luo, Songxuan Zhang, Yingchen Ju, Qiong Gu (D), Jun Xu (D), Xiang-Lei Yang (D) \& Huihao Zhou

Correction to: Nature Communications https://doi.org/10.1038/s41467-021-21902-0, published online 12 March 2021.

The original version of this Article contained an error in the author affiliations.

Affiliation number 1 incorrectly read 'Guangdong Provincial Key Laboratory of Chiral Molecule and Drug Discovery, Sun Yat-sen University, Guangzhou 510006, China’.

This has now been corrected in both the PDF and HTML versions of the Article to 'Guangdong Provincial Key Laboratory of Chiral Molecule and Drug Discovery, School of Pharmaceutical Sciences, Sun Yat-sen University, Guangzhou 510006, China'.

Published online: 29 April 2021

(c) Open Access This article is licensed under a Creative Commons Attribution 4.0 International License, which permits use, sharing, adaptation, distribution and reproduction in any medium or format, as long as you give appropriate credit to the original author(s) and the source, provide a link to the Creative Commons license, and indicate if changes were made. The images or other third party material in this article are included in the article's Creative Commons license, unless indicated otherwise in a credit line to the material. If material is not included in the article's Creative Commons license and your intended use is not permitted by statutory regulation or exceeds the permitted use, you will need to obtain permission directly from the copyright holder. To view a copy of this license, visit http://creativecommons.org/licenses/by/4.0/.

(C) The Author(s) 2021 